\title{
"INSIGHTS INTO LAVA FOUNTAIN ERUPTIONS AT MT. ETNA BY IMPROVED SOURCE LOCATION OF THE VOLCANIC TREMOR,
}

\author{
Salvatore Moschella ${ }^{1, *}$, Andrea Cannata ${ }^{2,3}$, Giuseppe Di Grazia $^{3}$, Stefano Gresta $^{1}$ \\ (1) Dipartimento di Scienze Biologiche, Geologiche e Ambientali, Università degli Studi di Catania, Catania, Italy \\ (2) Dipartimento di Fisica e Geologia, Università degli Studi di Perugia, Perugia, Italy \\ (3) Istituto Nazionale di Geofisica e Vulcanologia, Osservatorio Etneo, Catania, Italy
}

Article history

Receveid October 16, 2017; accepted July 12, 2018.

Subject classification:

Volcanic tremor; Site amplification factors; Site correction; Mt. Etna; Lava fountains.

\begin{abstract}
We analysed volcanic tremor recorded during ten lava fountain eruptions at Mount Etna volcano over the second half of 2011. The seismic signal, recorded by a network of 19 broadband stations, was corrected for site effects. The site amplification factors obtained for all the seismic stations were calculated using 18 regional earthquakes. To quantitatively estimate the goodness of the site correction, the volcanic tremor source locations obtained by using site corrections were compared with those performed without such corrections. The seismic signal was filtered in two different frequency bands before applying correction: (i) the band 1-2 Hz, which contains most of the tremor energy, and (ii) the band 5-10 Hz, in which, likely due to scattering phenomena, the assumption of isotropic radiation behind the volcanic tremor source location method is valid. The results revealed that the seismic signal correction for site effects improved the tremor location results. Such improved tremor locations, together with volcanological and geodetic data, allowed us to identify two distinct periods characterised by different tremor locations during lava fountains (July - August 20 and August 20 - November 15). Such differences were probably due to magma recharge phenomena, taking place during the former period.
\end{abstract}

\section{INTRODUCTION}

Volcanic tremor is the most distinctive seismic signal recorded at active volcanoes; its duration varies from minutes to days, and in some cases months or even more [Chouet, 1996]. The presence of this seismic signal is sometimes interpreted [McNutt, 2005] as the sign of an imminent or ongoing eruption. McNutt [1987] compiled a database of over 1100 cases of tremor observed on more than 84 volcanoes and found that approximately $60 \%$ of cases of tremor are accompanied by eruptions. Volcanic tremor recorded during eruptions is often associated with the upward migration of magma and gases through the vent, and includes information on eruption dynamics and kine- matics of magma movement [McNutt and Nishimura, 2008]. Volcanic tremor with its variations over time of both amplitudes and spectral characteristics is one of the most useful signals to understand the physical processes controlling explosive eruptions [Sparks et al., 2012] and detect explosive activity [e.g. Cannata et al., 2008; Messina and Langer, 2011]. Volcanic early warning tools based on seismic tremor have already been implemented, e.g., for Mount Etna [Langer et al., 2011; D’Agostino et al., 2013; Cannavò et al., 2017], Piton de la Fournaise [Battaglia, 2003], and for many other active volcanoes around the world. However, changes in volcanic tremor by themselves do not ensure the occurrence of an eruption since an increase in tremor amplitude can be recorded without any subsequent eruption [McNutt, 1992; Privitera et al., 
2003]. Worldwide observations of volcanic tremor show a large variability in time durations, signal amplitudes, and frequencies content. This wide variety indicates that volcanic tremor is probably the result of different processes [Chouet and Matoza, 2013].

At Mount Etna, the behaviour of volcanic tremor strongly reflects the evolution of explosive activity: the tremor amplitude gradually increases up to a maximum at the same time as the climax of the eruption, then decreasing rapidly and returning to a "normal" level at the end of explosive phase [e.g. Alparone et al., 2003; Cannata et al., 2008]. This pattern has been continuously observed during the lava fountain eruptions, that took place at the New South-East Crater (NSEC) and Voragine (VOR) during 2011-2016 [e.g. Viccaro et al., 2014; Cannavò et al., 2017]. Changes of volcanic tremor features during volcanic activity involve both amplitude and source location, which generally gets shallower and closer to the eruptive vent during the explosive eruptions [e.g. Di Grazia et al., 2006; Patanè et al., 2008; Viccaro et al., 2014]. Concerning volcanic tremor source location, it is impossible to use techniques based on the inversion of the arrival time of the seismic phases (used for earthquake localization). Except for the techniques developed for seismic arrays [e.g. Metaxian et al., 1997; Almendros et al., 2001], most of the methods used to locate tremor are based on spatial distribution of amplitudes [e.g. Battaglia and Aki, 2003; Di Grazia et al., 2006; Kumagai et al., 2010; Jones et al., 2011].

In this study, the location method of Di Grazia et al. [2006] and Cannata et al. [2013] will be applied to the volcanic tremor seismic signals recorded during ten lava fountain eruptions, taking place at the NSEC in the second half of 2011. Seismic signals are influenced not only by processes occurring at the source, but also by complex propagation and site effects [e.g. Neuberg and Pointer, 2000]. Hence, we will remove the site effects from the original seismic signals, and compare the tremor source locations obtained with and without the site corrections.

The study will also consider two different frequency bands in which the signal was filtered before being corrected for site effects, 1-2 Hz and 5-10 Hz. By comparing the volcanic tremor source locations obtained for the two different frequency bands, further indications on the volcanic tremor source might be obtained.

\section{DATA ANALYSIS}

\subsection{SPECTRAL ANALYSIS AND RMS AMPLITUDE}

At Mount Etna, analysis of the seismo-volcanic signals, such as volcanic tremor, long-period (LP) events and very long-period (VLP) events, is performed on the recordings of 19 seismic stations, equipped with threecomponent broadband (40s cutoff period) seismometers (Trillium, Nanometrics ${ }^{\mathrm{TM}}$ ), acquiring in real time at a sample rate of $100 \mathrm{~Hz}$ (Figure 1).

On the recorded seismic signal, we performed spectral analysis by applying the Short Time Fourier Transform (STFT), considering 10.24 second time windows. Together with the spectrogram, a plot of peak frequencies was obtained. The spectral analysis of the seismic signals was performed on a summit station (EBEL) and a peripheral station (ECZM; Figure 1). For each eruptive event, a 24-hour time interval was considered.

The results of the spectral analyses, carried out for all the eruptive events analysed in this study, show that most of volcanic tremor energy for each lava fountain is mainly radiated in the band $1-2 \mathrm{~Hz}$ both in the summit and in the peripheral stations (Figure 2).

To calculate the amplitude of the seismic signal recorded at the various stations, the root mean square (RMS) of the seismic amplitude was computed. Because the amplitude RMS is required in specific frequency bands, the signal has been filtered in the frequency band 1-2 Hz and then the RMS was calculated. Such a parameter is particularly useful for defining the amplitude of long-duration signals such as volcanic tremor. After taking into account the seismic signals recorded by the various stations and filtering them into a specific frequency band, an RMS value was calculated for each 10 second-long window. In Figure 2, the time series of RMS amplitudes of the vertical component of the seismic signal recorded at EBEL and ECZM stations, filtered in the band 1-2 $\mathrm{Hz}$, are shown.

The results of the RMS amplitudes, computed for all the eruptive events analysed in this study, show that each eruption is accompanied by an increase of the seismic RMS before the paroxysmal phase, when the maximum amplitudes are reached (Figure 2).

\subsection{SITE EFFECTS CORRECTION METHOD}

As afore mentioned, seismic signals are influenced not only by processes occurring at the source, but also by both propagation and site effects, particularly relevant for seismic stations located in volcanic areas [e.g. Neuberg and Pointer, 2000]. To better understand the processes occurring at the source, we tried to remove the site effects for each station from the original seismic signal using regional earthquake recordings.

The amplitude of the signal $A_{j}(f)$ observed at the $j$-th station for a given seismic event and for a given frequency $f$ can generally be written as the product of the following terms [e.g. Bath, 1974]: 


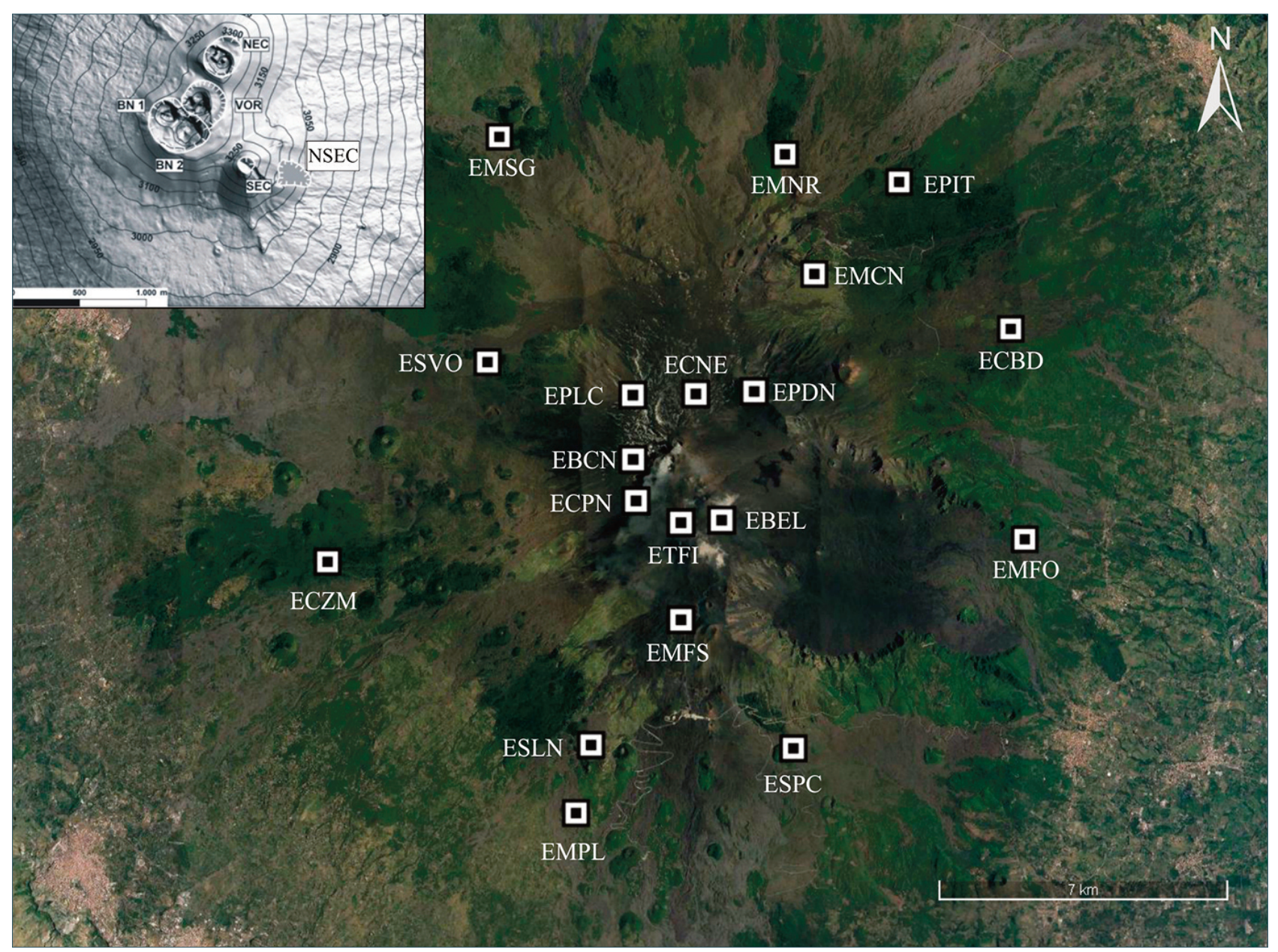

FIGURE 1. Etna orthophoto (GoogleEarth) with the location of the 19 broad-band seismic stations (white and black squares) used for the analysis of seismo-volcanic signals. The digital elevation model in the upper left corner shows the distribution of the five summit craters (VOR Voragine, BN Bocca Nuova, NEC North East Crater, SEC South East Crater, NSEC New South East Crater) at the date of 22/11/2011. The black contour represents the altitude isolines with spacing of $50 \mathrm{~m}$ (from INGV - Etna weekly bulletin of 22/11/2011).

$$
A_{j}(f)=K_{j}(f) G_{j}(f) S_{j}(f) T_{j}(f)
$$

where $K_{j}$ represents the source term including the radiation pattern to the $\mathrm{j}$-th station, $G_{j}$ the instrument response curve, $S_{j}$ the site effects, and $T_{j}$ the path effects. While the term $G_{j}$ can be easily removed by using the seismometer characteristics, the path, site, and source effects $\left(T_{j}, S_{j}\right.$ and $\left.K_{j}\right)$ are generally unknown and station-dependent. However, if earthquakes are very distant from the seismic network, it can be inferred that path and source's directivity are common to all stations [Matsubara et al., 2004]. For this reason, such effects will be generally indicated as $T(f)$ and $K(f)$, respectively.

A relative site amplification factor (hereafter referred to as $\left.\operatorname{SAF}_{j}(f)\right)$ can be obtained at the $j$-th station, as the ratio between site amplification factor and the average of the site effects computed on all the considered stations (or on a group of reference stations) $\tilde{S}$ (f) by the following equation [Matsubara et al., 2004]:

$$
\frac{A_{j}(f)}{\widetilde{A}(f)}=\frac{K(f) S_{j}(f) T(f)}{\frac{1}{N} \sum_{j=1}^{N} K(f) S_{j}(f) T(f)}=\frac{S_{j}(f)}{\frac{1}{N} \sum_{j=1}^{N} S_{j}(f)} \equiv S A F_{j}(f)(2)
$$

where $\tilde{A}(f)$ is the average amplitude on all stations (or on a group of reference stations) for the considered event and $N$ is the number of reference stations. Matsubara et al. [2004] calculated relative site amplification factors by this method for seismic stations located in Mt. Usu, Japan, considering a teleseismic event.

To calculate $S A F$ of the stations used for seismo-volcanic signals investigations at Mount Etna, we chose to consider only regional earthquakes as: (i) they are sufficiently distant that signals at Mount Etna stations have equal path and source effects; (ii) they are not so distant that the higher frequency signal components (e.g. > $0.5 \mathrm{~Hz}$ ) are completely attenuated (as for teleseismic earthquakes showing generally energy at frequencies $<0.5 \mathrm{~Hz}$ ). Recordings of 18 earthquakes, that occurred in the Mediterranean area between 2009 and 2014 with a magnitude ranging from 5.1 to 6.9 (location and magnitude data were obtained from http://earth- 


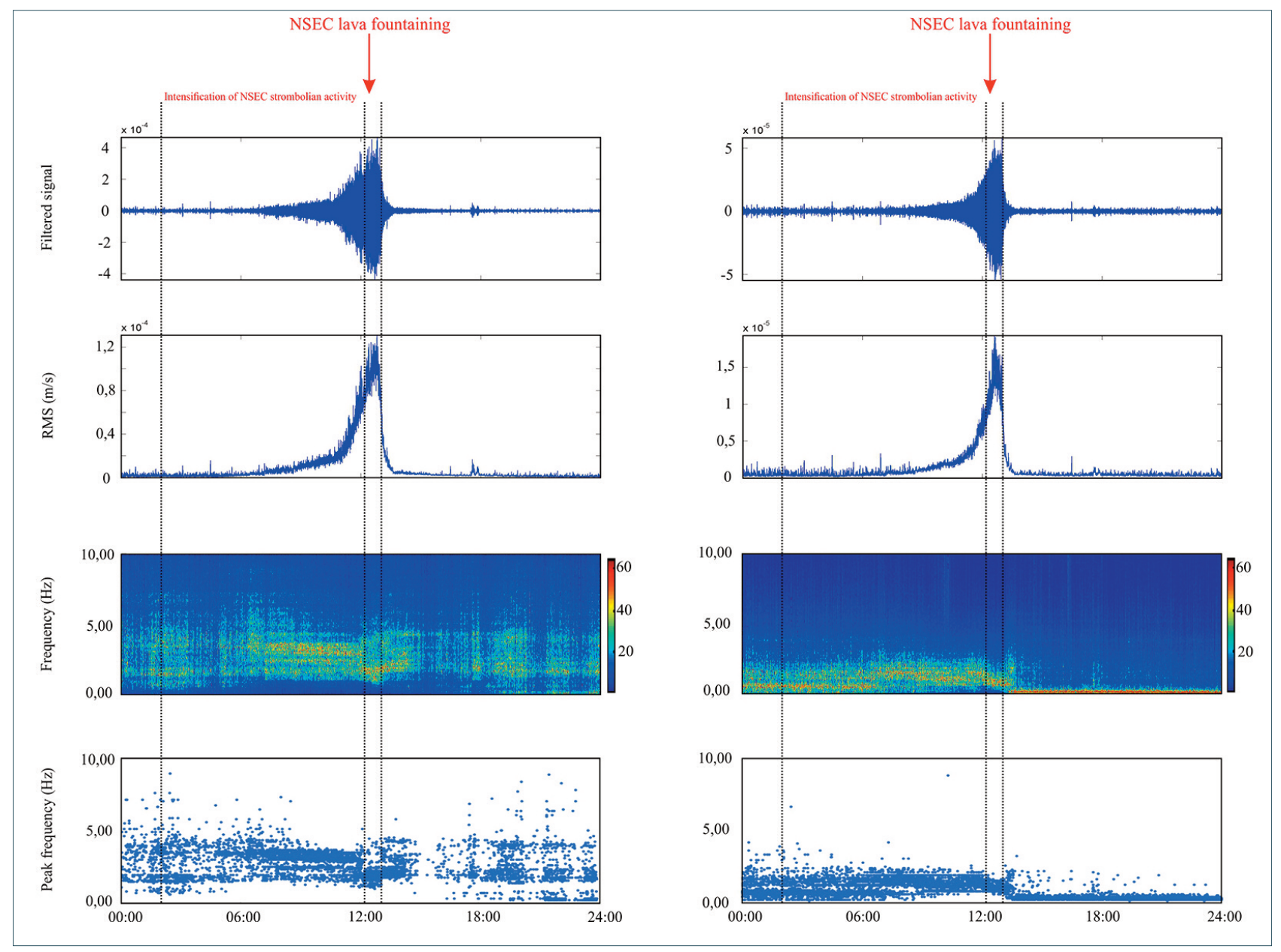

FIGURE 2. From top to bottom: vertical component of seismic signal filtered in the band 1-2 Hz, RMS amplitude time series of vertical component of seismic signal, normalized STFT and peak frequency at EBEL (left) and ECZM (right) stations during 19/9/2011.

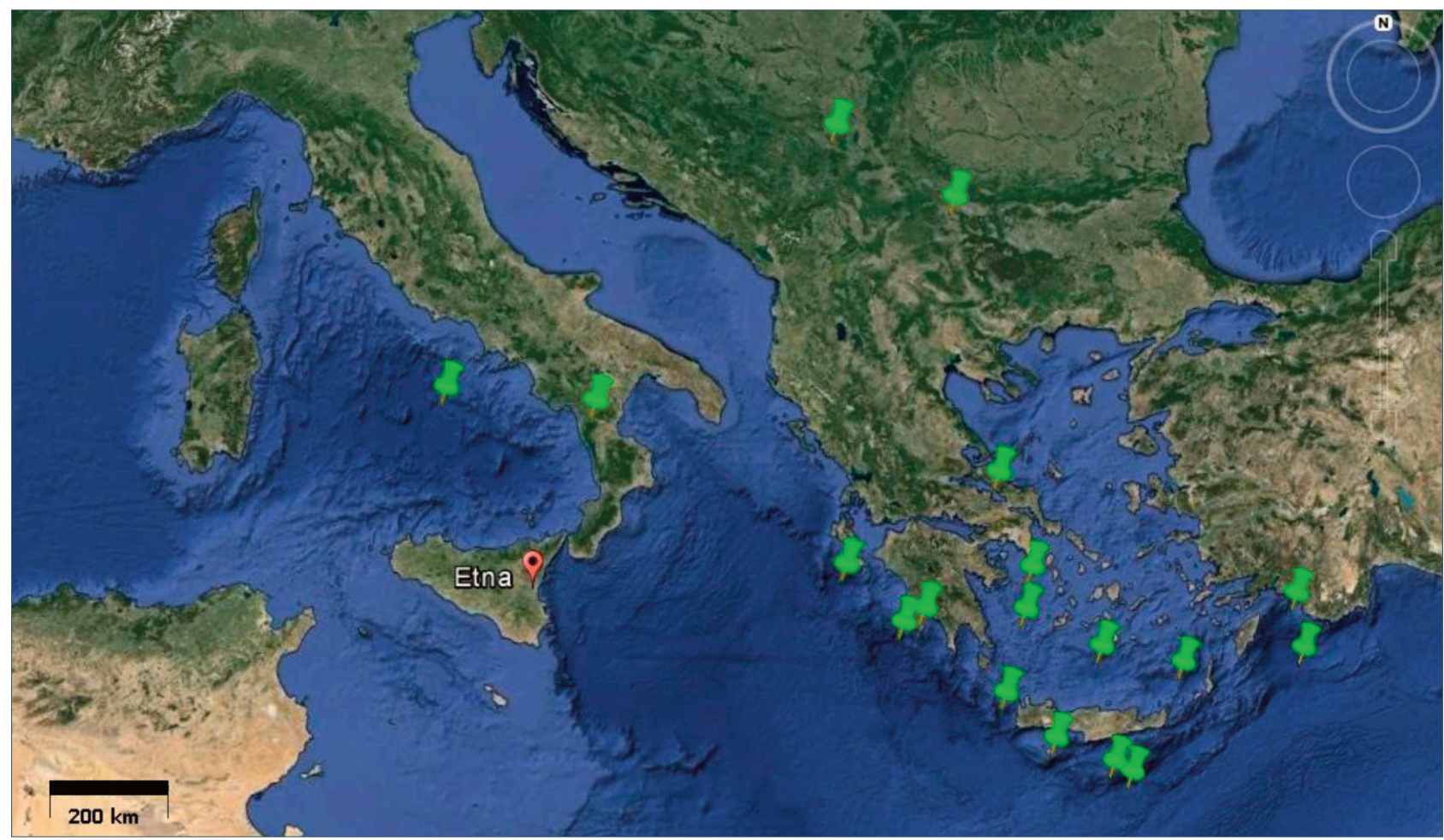

FIGURE 3. Epicentral distribution of the eighteen regional earthquakes with magnitude ranging from 5.1 to 6.9 that took place from 2009 to 2014 in the Mediterranean area. 


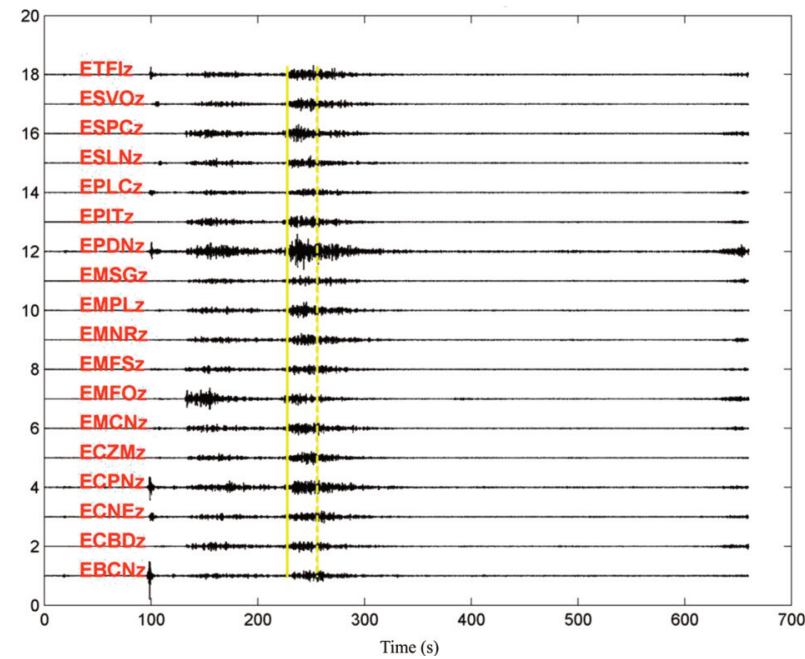

FIGURE 4. Seismic signals recorded by Etna seismic stations and filtered at 1-2 Hz, showing a regional earthquake that occurred in Greece on 16/06/2013 of magnitude 6.0. The yellow box highlights the window of 20 seconds extracted from the arrival of $\mathrm{S}$ waves.
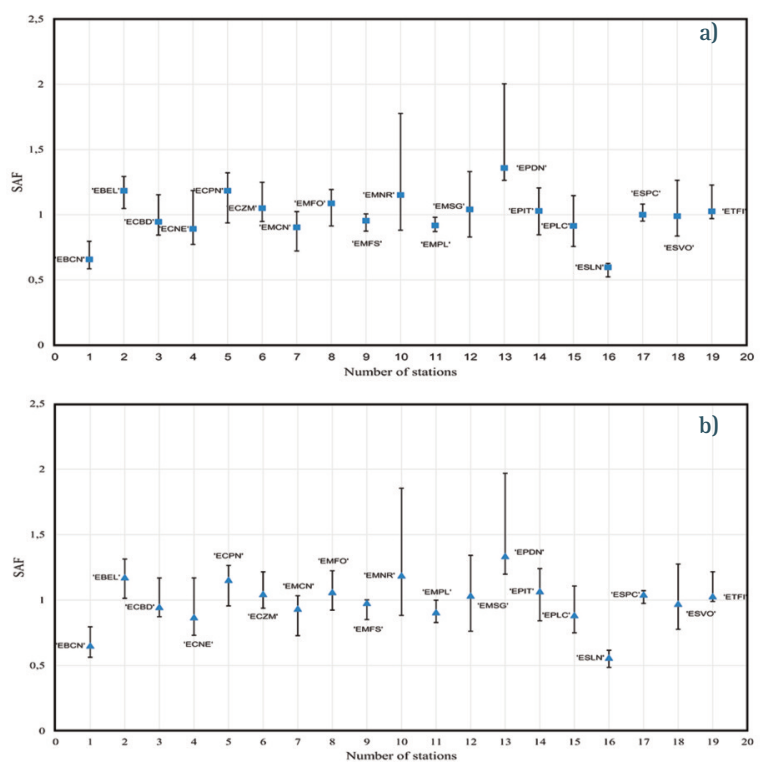

FIGURE 5. Relative SAF with error bar given by the interquatile range obtained for all the stations in the frequency band 1-2 $\mathrm{Hz}$ (a) and 5-10 Hz (b).

quake.usgs.gov/earthquakes/search/), were analysed (Figure 3).

In order to estimate $S A F, 20$-second-long seismic windows, starting from the S-waves onset, were extracted, filtered for the frequency band of interest (1-2 $\mathrm{Hz}$ and 5-10 Hz), and the RMS amplitudes of the resultant of the three signal components were calculated (Figure 4).

Subsequently, the ratio between RMS amplitudes at each station and the average RMS amplitudes at the

\begin{tabular}{ll} 
Station & SAF \\
EBCN & 0.76 \\
EBEL & 1.15 \\
ECBD & 0.93 \\
ECNE & 0.98 \\
ECPN & 1.18 \\
ECZM & 0.96 \\
EMCN & 0.95 \\
EMFO & 0.98 \\
EMFS & 0.98 \\
EMNR & 1.03 \\
EMPL & 1.00 \\
EMSG & 1.00 \\
EPDN & 1.34 \\
EPIT & 1.02 \\
EPLC & 0.90 \\
ESLN & 0.61 \\
ESPC & 1.05 \\
ESVO & 0.97 \\
ETFI & 1.06 \\
\hline
\end{tabular}

TABLE 1. The relative amplification factors calculated for each seismic station and for the two analyzed frequency bands.

four stations that showed the smallest data gaps (they recorded at least 16 earthquakes out of 18), taken as reference stations (ECBD, ECZM, EMPL, ESPC), was calculated. This was done for each station and for each analysed earthquake. Hence, a relative amplification factor was calculated on the signal output. $S A F$ values given by the ratio between RMS amplitudes at each station and the average RMS amplitudes at all stations was also calculated, but no significant variation between the two values was observed.

Finally, the median values of the ratios obtained for all the regional earthquakes (one per each station and frequency band) were computed and considered relative $S A F$ with the error bar given by the interquartile range calculated for each station and frequency band (Figure 5). The median values were estimated in place of the average values, because they are less affected by outliers. $S A F$ values at low frequencies (1-2 Hz) are very similar to those achieved at high frequencies $(5-10 \mathrm{~Hz})$. For this reason, a unique $S A F$ value was obtained for each station by averaging the values of $1-2 \mathrm{~Hz}$ and 5$10 \mathrm{~Hz}$ (Table 1). Most stations show SAF values close to 1, with the exception of a few, such as EPDN and ESLN displaying the highest and lowest $S A F$, respectively. 
Once the signals are corrected for the instrumental response and site effects, the differences in amplitudes at the various stations depend only on path and source effects.

\subsection{VOLCANIC TREMOR LOCATION METHOD AND SITE EFFECT CORRECTION RESULTS}

To locate volcanic tremor source centroids at Mount Etna, a method based on the seismic amplitude decay was applied, assuming a propagation in a homogeneous medium [Di Grazia et al., 2006; Patané et al., 2008; Cannata et al., 2013]. In particular, tremor source location was estimated by using a grid - search approach [e.g. Gottschammer and Surono, 2000; Battaglia et al., 2005; Di Grazia et al., 2006] and assuming that seismic amplitude (A) decays with the distance (r) according to the general law:

$$
A(f, r)=A_{0}(f) r^{-b} e^{-\alpha r}, \quad \alpha=\frac{\pi f}{Q c}
$$

where $f$ is the frequency, $c$ the velocity, $b$ the exponent which takes values of 0.5 or 1 for the cases of surface and body waves, respectively. $Q$ represents the raypath-averaged quality factor. The equation (3) can be linearized taking the logarithm on both sides as follows:

$$
\ln A_{i}+\alpha r_{i}=\ln A_{0}-b \ln r_{i}
$$

where $A_{i}$ is the RMS amplitude measured at the $i_{t h}$ station, $\alpha$ is the frequency-dependent absorption coefficient and $r_{i}$ is the corresponding source-to-receiver distance. In the equation (4), $\ln A_{O}$ and $b$ can be considered the intercept and the slope of the linear equation, respectively. Then the source location of tremor is found on the basis of the $\mathrm{R}^{2}$ linear regression coefficient obtained for each point on a 3-D grid centred underneath the craters [Di Grazia et al., 2006]. The absorption coefficient $\alpha$ is systematically changed (in the interval $0 \leq \alpha \leq 0.4$ with step of 0.01) for each grid point with the aim of improving the goodness of fit. The $\alpha$ value allowing to maximize $\mathrm{R}^{2}$ is chosen [Patanè et al., 2008; Cannata et al., 2010].

The volcanic tremor signal, recorded during ten lava fountains taking place during the second half of 2011, was analysed. Indeed, to obtain perfectly comparable location results, it was necessary to identify eruptive events recorded by all the 19 seismic stations, used to study seismo-volcanic signals. The seismic signals of the 10 lava fountains indicated in Figure 6a show such an important feature. Moreover, the choice to analyse only volcanic tremor recorded during lava fountains is due to the fact that during such paroxysms the amplitude of volcanic tremor at all the used stations becomes
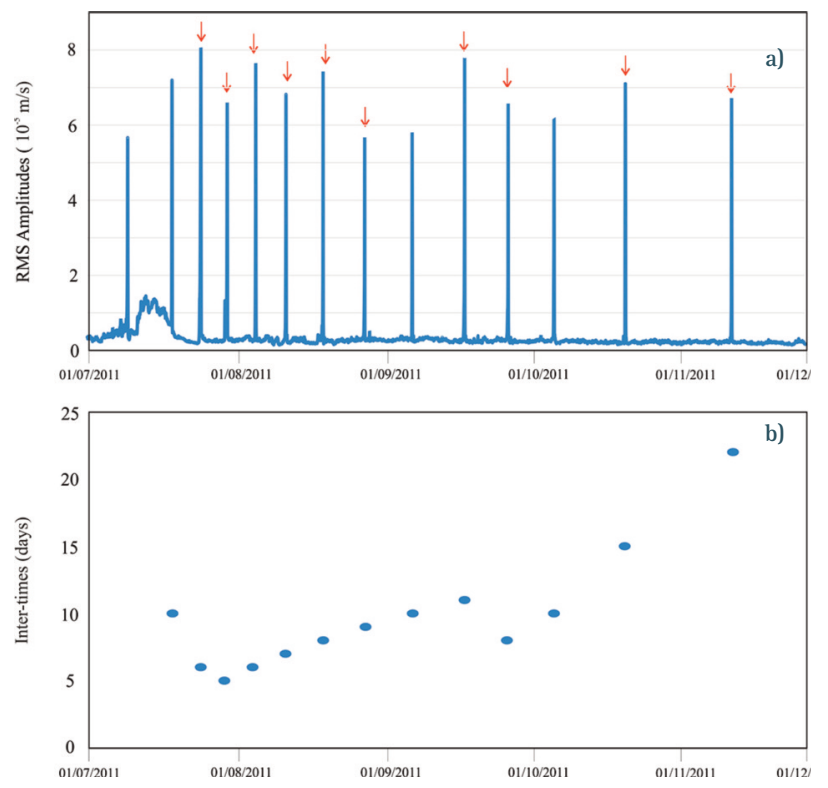

FIGURE 6. (a) Temporal variation of seismic RMS amplitudes calculated on 60 minute windows of the vertical component of the signal recorded by the ECPN station in the second half of 2011. The amplitude spikes represent the increases in tremor amplitude at the same time as lava fountains at NSEC, the red arrows represent those chosen for this study. (b) Temporal variation of the inter-times between consecutive lava fountain eruptions.

predominant with respect to the amplitudes of other possible seismic sources. Hence, the assumption of a unique seismic source during paroxysmal activities is more reasonable. Finally, as shown in previous papers [e.g. Patanè et al., 2013; Viccaro et al., 2014], during such events the tremor sources turn out to be located nearby the active vents.

The seismic signal, recorded during such 10 lava fountain eruptions, was filtered into two different frequency bands: (i) 1-2 Hz: which, as afore mentioned, contains most of the volcanic tremor energy; (ii) 5-10 $\mathrm{Hz}$ : where, because of scattering phenomena, the assumption of isotropic radiation behind the volcanic tremor source location method should be valid even for resonating conduit/cracks [Kumagai et al., 2010; 2011].

To obtain the amplitude of the volcanic tremor and locate its source, the 25th percentile of RMS amplitude values, falling in time windows of 20 minutes, was calculated. The use of percentiles allows effectively reducing the amplitude contribution of seismic transients (LP events, VLP events, volcano-tectonic earthquakes, and so on) and thus considering only the amplitude of the continuous background tremor signal [Di Grazia et al., 2006; Patanè et al., 2008; Cannata et al., 2013]. In order to obtain amplitudes corrected for the site effects, such a RMS 25th percentile time series was divided by the relative amplification fac- 

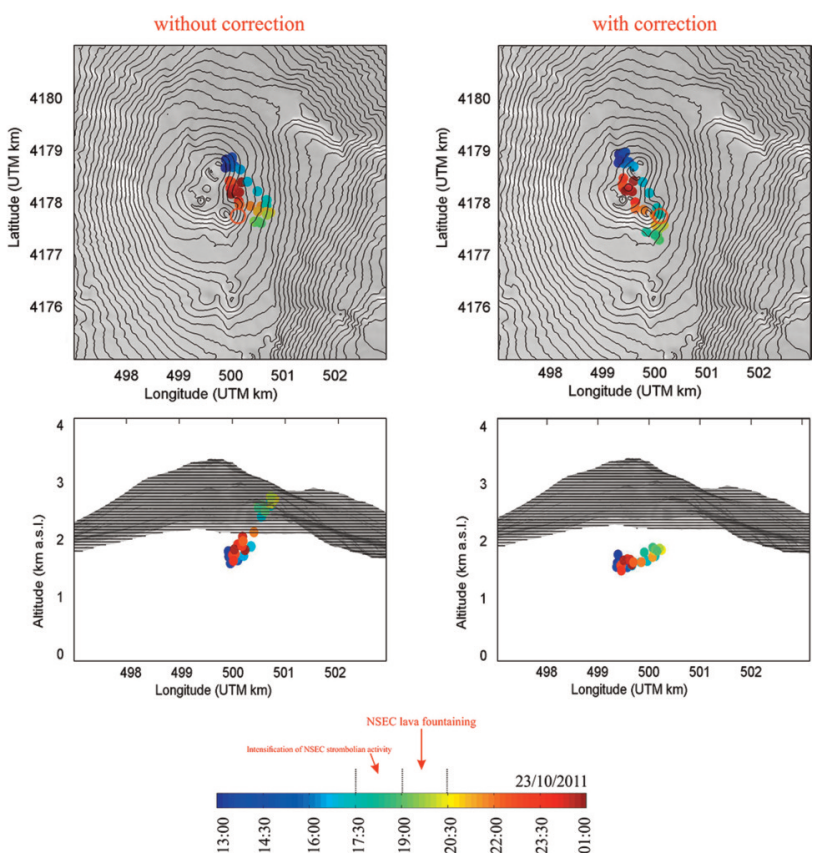

FIGURE 7. Distribution on map (top) and W-E section (bottom) of the volcanic tremor centroids in the frequency band $1-2 \mathrm{~Hz}$ without correction for site effects (left) and with correction (right) for the 19/9/2011 lava fountain eruption. The dot color indicates the time (see bottom colorbar). The lava fountain activity time period is represented by the green color. The red empty circle in map indicates the NSEC location.

tor $S A F$ of the considered station.

Figure 7 shows the spatial variations of the volcanic tremor centroid on map and W-E section of the volcano within 24 hours interval, comprising a lava fountain event, at intervals of 20 minutes.

In order to quantitatively compare the locations, obtained by correcting the amplitudes for site effects, with those performed without site effect correction, we focused on a shorter time period of 12 hours, including the eruptive event. In particular, for the two analysed frequency bands we compared the following parameters: (i) coordinates of the centroids (Figures 8 a, b, c, f, g, h); (ii) quadratic correlation coefficient $\mathrm{R}^{2}$ (Figures $8 \mathrm{~d}$, i); (iii) distances of each centroid from the NSEC (Figures 8e, j).

In addition, to compare the volcanic tremor locations obtained during distinct lava fountain eruptions, firstly the time intervals of the sustained lava fountains were identified, with a duration ranging from thirty minutes to two hours [the information about the start and end times of sustained lava fountains phases were taken from Behncke et al., 2014]. Then, median values of the volcanic tremor centroid coordinates, $\mathrm{R}^{2}$ and centroid-NSEC distances were calculated and plotted in Figure 9.

Finally, to assess the stability of the source locations, a jackknifing procedure [also called "leave one out"; e.g. Efron, 1982] was applied for each centroid by leaving one station out at a time [for further details see Cannata et al., 2013]. The errors of volcanic tremor centroid latitude, longitude and altitude, calculated by applying the above-described method, were respectively of about 700 $\mathrm{m}, 500 \mathrm{~m}$ and $850 \mathrm{~m}$ in the $1-2 \mathrm{~Hz}$ frequency band, and of about $150 \mathrm{~m}, 250 \mathrm{~m}$ and $200 \mathrm{~m}$ in the $5-10 \mathrm{~Hz}$ frequency band. Although the errors associated to each location are greater than the difference between the distances of the centroids obtained with the two methods, the two location clouds are separated from each other, suggesting changes in tremor location obtained with and without corrections.

\section{DISCUSSION}

From the results shown in Figures 8 and 9, the following considerations can be made about the difference between the locations, obtained by applying the site effect corrections, and the locations without such corrections:

- The centroids obtained applying the site effect corrections are shifted to the West (before, during and after the fountain activity) compared to those located without corrections both in the 1-2 Hz and 5$10 \mathrm{~Hz}$ frequency bands (Figures 8a, 8f, 9a, 9f).

- The centroids obtained applying the site effect corrections are shifted to the South compared to those located without corrections only in the frequency range $1-2 \mathrm{~Hz}$, while in the $5-10 \mathrm{~Hz}$ band there are no significant differences (Figures $8 \mathrm{~b}$, 8g, 9b, 9g).

- The centroids altitudes obtained applying the site effect corrections are deeper than those located without corrections in the frequency range 1-2 Hz, while at 5-10 Hz they are located slightly shallower than those obtained without corrections (Figures 8c, 8h, 9c, 9h).

- The $\mathrm{R}^{2}$ quadratic correlation coefficient in both the analysed frequency bands shows slightly higher values for the locations obtained applying the site effect corrections, ranging from 0.85 to 0.94 (Figures 8d, 8i, 9d, 9i).

- The centroid-NSEC distances are shorter for the locations obtained applying the site effect corrections in the frequency band $1-2 \mathrm{~Hz}$; on the other band, in the frequency band $5-10 \mathrm{~Hz}$ distances in both corrected and non-corrected cases are almost coincident for the first five studied eruptive events, while they are higher in the corrected cases than in the non-corrected cases in the remaining eruptive events (Figures 8e, 8j, 9e, 9j). 

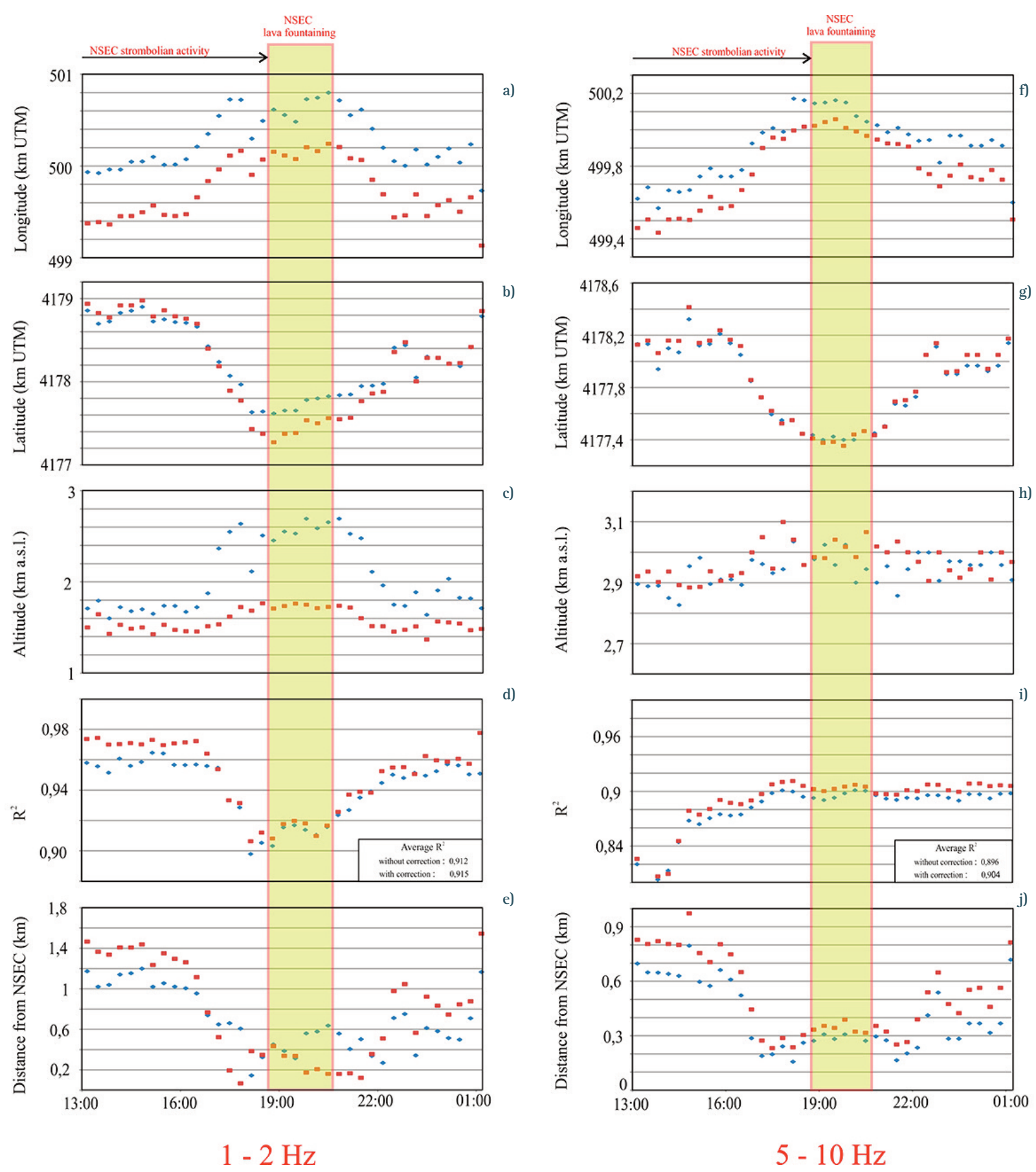

FIGURE 8. Temporal variation of the coordinates of the tremor centroids ( $\mathrm{a}, \mathrm{b}, \mathrm{c}, \mathrm{f}, \mathrm{g}, \mathrm{h}$ ), the $\mathrm{R}^{2}$ with the comparison between the average values obtained with and without corrections in the low right corner $(\mathrm{d}, \mathrm{i})$ and the centroid distance from the $\operatorname{NSEC}(e, j)$ in the frequency bands 1-2 Hz (left) and 5-10 Hz (right) for the 23/10/2011 lava fountain eruption. Red squares show locations obtained by applying the correction, blue diamonds locations obtained without correction. The yellow rectangle indicates the time interval of sustained lava fountain.

Focusing on the time intervals of sustained lava fountain, the centroids obtained applying the site effect corrections are shifted towards SW (and at lower altitude in the frequency band 1-2 Hz) than those obtained without corrections. The slightly higher $\mathrm{R}^{2}$ values and the shorter distances from NSEC at least in the frequency band 1-2 $\mathrm{Hz}$ confirm that the site corrections improved the location results.

\subsection{COMPARISON BETWEEN THE TWO FREQUENCY BANDS}

In Figure 9 the different results obtained for the two analysed frequency bands during time intervals of sustained lava fountain, in terms of coordinates of the centroids, $\mathrm{R}^{2}$ values and centroid-NSEC distances are shown. It is evident how in the frequency band 5-10 Hz: centroids are shallower (mostly located at $\sim 3 \mathrm{~km}$ 
a.s.l.; Figure 9h) and south-westward shifted (Figures $9 f, g), R^{2}$ values are slightly lower (ranging from 0.89 to 0.92; Figure 9i), and centroid-NSEC distances are generally shorter (Figure 9j).

Despite the greater precision in localization, suggested by the shorter centroid-NSEC distances, obtained for 8 events out of 10 (Figures 9e,j), the 5-10 Hz locations do not provide any significant indication about the vertical migration of the tremor source, which is appreciable in the frequency band 1-2 Hz.
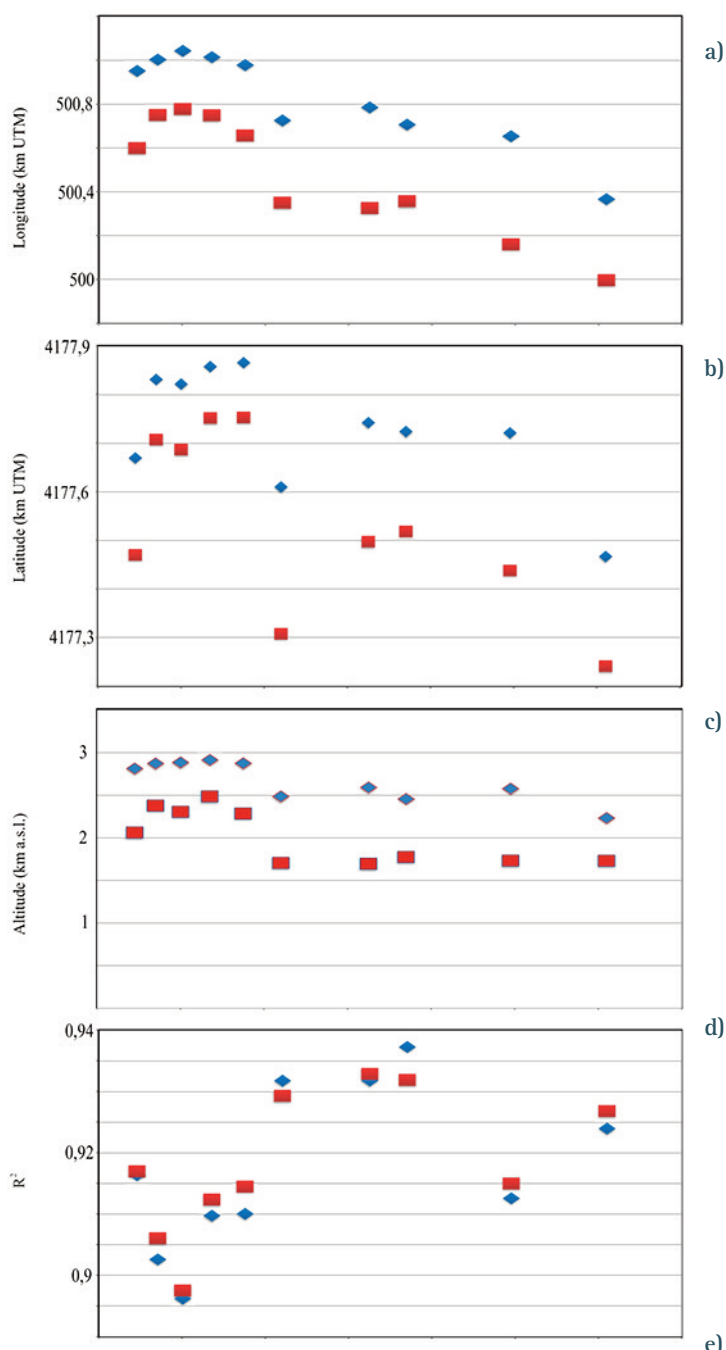

c)

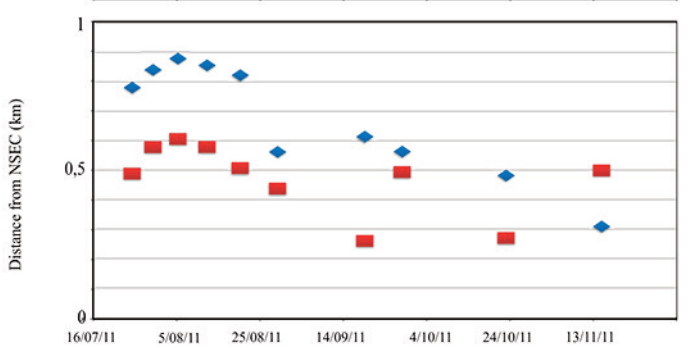

$1-2 \mathrm{~Hz}$
A further difference between results from the two frequency bands can be observed by calculating the contour of the volcanic tremor amplitude isolines, obtained from the $25^{\text {th }}$ percentile of the RMS amplitudes, corrected for site effects, through a spline-type cubic interpolation on 20-minute-long windows. Focusing on the amplitude spatial distributions obtained during the paroxysmal phases, the maximum RMS values are observed in the stations near the eruptive vent. There is also a marked difference in the distribution of the am-
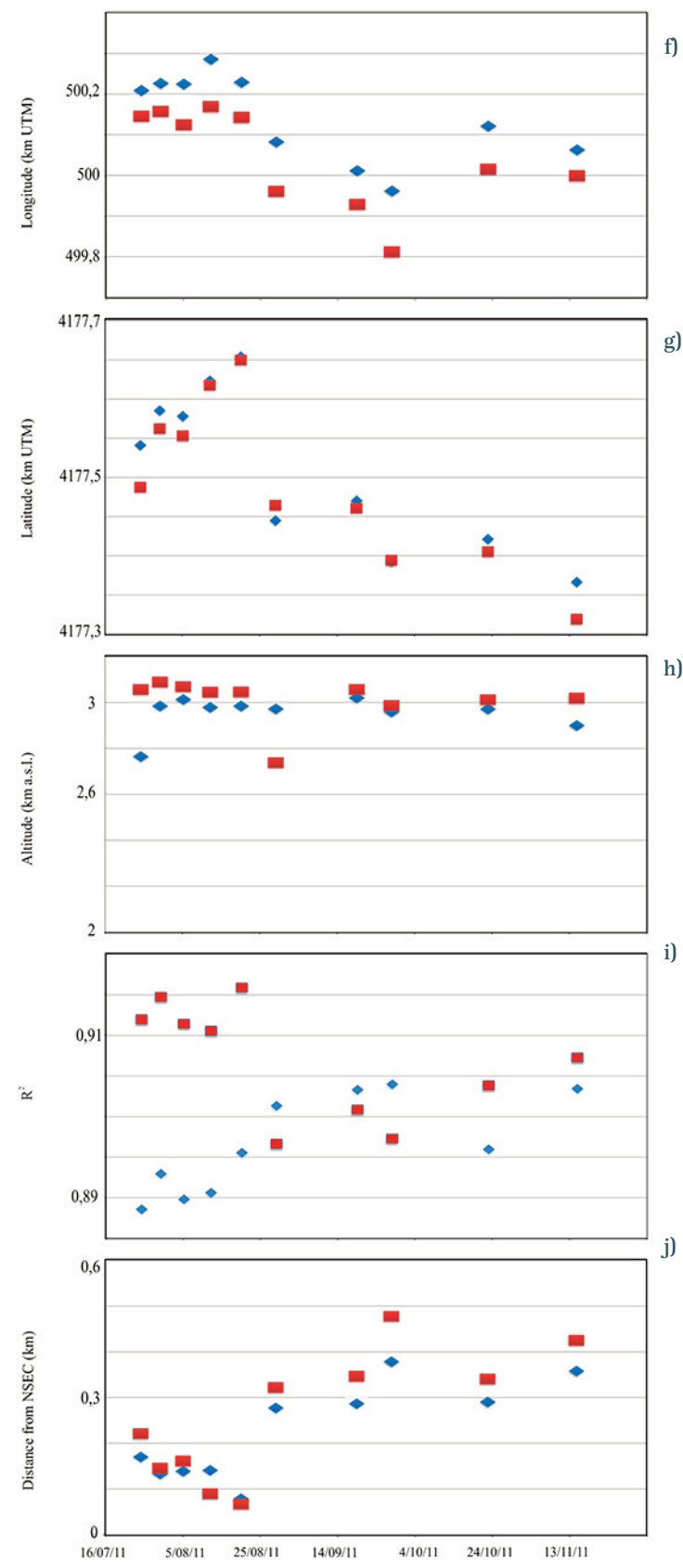

$5-10 \mathrm{~Hz}$

FIGURE 9. Temporal variation of the median values of the coordinates of the tremor centroids (a, b, c, f, g, h), $\mathrm{R}^{2}(\mathrm{~d}$, i) and centroid distance from the $\operatorname{NSEC}(e, j)$ in the frequency ranges $1-2 \mathrm{~Hz}$ (left) and 5-10 Hz (right) for all the considered lava fountain eruptions. Red squares show locations obtained by applying the correction, blue diamonds locations obtained without correction. 


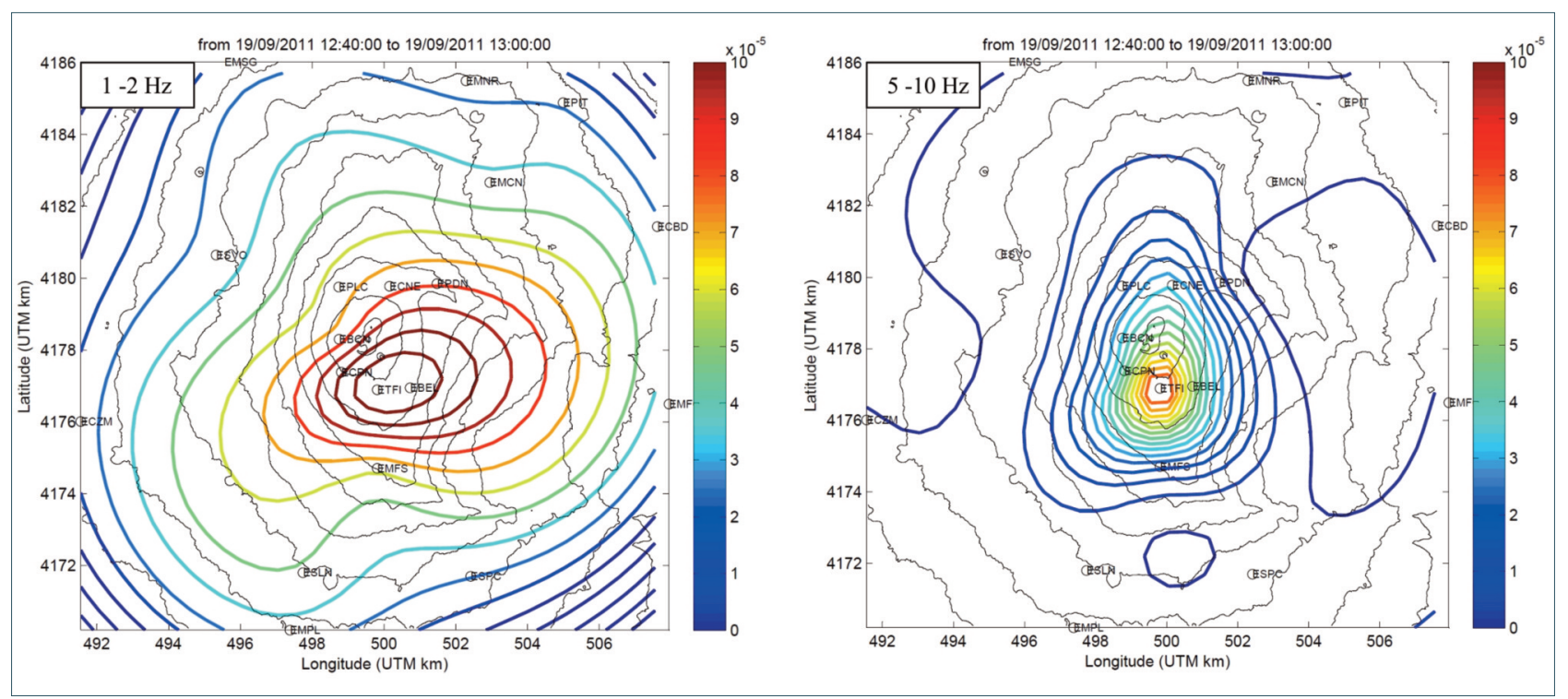

FIGURE 10. Contour plots showing the spatial distribution of volcanic tremor amplitude calculated for the frequency bands 1-2 $\mathrm{Hz}$ (left) and 5-10 Hz (right) in the temporal interval of sustained lava fountain of the 19/09/11 eruption.

plitudes between the 1-2 $\mathrm{Hz}$ and $5-10 \mathrm{~Hz}$ frequency bands (Figure 10).

It is evident how, for low frequencies, the contour gets stretched in an approximately ENE-WSW direction (the major axis direction of the calculated isolines) and the amplitudes decrease very slowly with distance. As for high frequencies, the amplitude distributions show a rapid decrease in the amplitude value with the distance and seem to be more isotropic at least for the isolines with the larger amplitude values $\left(>5^{*} 10^{-5} \mathrm{~m} / \mathrm{s}\right.$ ), presenting an almost circular shape. These differences in contour shape in the two frequency bands have been confirmed by calculating the eccentricity values referred to the ellipses inscribed inside the amplitude isolines.

Such results likely confirm the conclusions by Kumagai et al. [2010; 2011], according to whom at higher frequencies the seismic scattering, caused by topography and medium heterogeneity, masks eventual source directivity and makes the isotropic radiation assumption valid. However, since the 1-2 Hz and 5-10 Hz tremor centroids show slightly different locations (especially in terms of altitude), we cannot exclude that the different isotropic/anisotropic features of the amplitude distribution could be due to different source geometries/orientations in the two distinct portions of plumbing system generating low and high frequency volcanic tremor.

\subsection{CYCLICAL CHANGES IN LAVA FOUNTAIN ERUP- TIONS: INTEGRATION OF SEISMIC, VOLCANOLOG- ICAL AND GEODETIC DATA}

Focusing on the median values of the centroid coordinates calculated with SAF correction in the frequency band 1-2 Hz, and in particular on the altitudes (Figure 9c), it is possible to identify two different periods: (i) the first one (July 25 - August 20) characterized by altitudes higher than $2 \mathrm{~km}$ a.s.l., while (ii) the second one (August 20 -November 15) by lower altitudes.

Such two periods do not differ from each other only for tremor source locations, but also for volcanological and geodetic characteristics. The RMS amplitude time series, calculated on the vertical component of the ECPN station from June to December 2011 on windows of 60 minutes (Figure 6a), clearly show the time of occurrence of the lava fountain eruptions. In particular, the lava fountains of July and August (the above-mentioned first period) show fairly regular short inter-times of about 5-7 days, while from the August 20 eruption (the above-mentioned second period) the inter-times between fountains progressively increase (Figure 6b).

These changes in lava fountain inter-times are common to Etna as also observed during the 1989 eruptions at the South-East crater [SEC; Privitera et al., 2003] and during the February-April 2013 fountain sequence at NSEC [Spampinato et al., 2015]. It is reasonable that a volcanic system is strongly non-linear and that only sporadically this can take linear behaviour [e.g. Privitera et al., 2003]. To determine exactly the course of eruptive phenomena, it would be necessary to know several parameters that are not always known a priori and very often are affected by large uncertainties. The causes of a variation in the "regular" trend shown by lava fountain eruptions, such as an increase in the inter-time between an eruption and the next one, or the change from a periodic to non-periodic behaviour, may be due to several factors. For instance, variations in: i) geometry of the magma conduits/shallow plumbing 
system; ii) magma content of gas and/or physical parameters, etc.

Similar short lasting periodic patterns are generally observed at Mt. Etna during banded tremor episodes, as observed in the second half of 2008 [Cannata et al., 2010]. It was inferred that the system generating "banded tremor" has analogies with the geyser systems in terms of behaviour (chaotic) and features [system geometry, quantity of water, heating rate and rock properties, such permeability and porosity; Cannata et al., 2010].

The eruption of August 20, 2011 therefore marks the beginning of a variation of eruptive dynamics. Further evidence, which could provide a possible explanation for the subdivision in the two periods, comes from the ground deformation data measured during the studied period. The Etna GPS network recorded rapid inflation between 20 May and 16 July and a rapid deflation from 16 July to 17 October 2011 [Patanè et al., 2013]. Inflation and deflation sources, detected by inversion of ground deformation pattern, were located below the summit area at a depth of $5 \mathrm{~km}$ b.s.l., interpreted as linked to pressurization mechanisms and subsequently depressurization inside a deep magma storage [Patanè et al., 2013].

At the same time as the rapid inflation and subsequent deflation of the volcanic edifice, the Bocca Nuova crater showed a brief period of Strombolian activity starting on July 12, 2011, accompanied by an increase in the amplitude of volcanic tremor and LP events [these are located below the summit area at about 2-3 $\mathrm{km}$ a.s.l.; Patanè et al., 2013], suggesting the pressurization of the superficial portion of the feeding system.

These observations have led to the hypothesis that during the period May-August 2011 gas-rich magma migrated from depth recharging both deeper ( $5 \mathrm{~km}$ b.s.l.) and shallower portions of the volcanic feeding system [Patanè et al., 2013]. Hence, the shorter inter-times and the shallower volcanic tremor sources could be due to these magma recharge phenomena.

\section{CONCLUDING REMARKS}

In this study, the volcanic tremor seismic signals recorded during ten eruptions of lava fountains taking place at the NSEC in the second half of 2011 were studied in terms of spectral content, site effect correction, source location, relation with volcanological and geodetic data. The following points summarize the main findings:

1. The results of the spectral analysis show that most of volcanic tremor energy for each lava fountain is radiated in the band $1-2 \mathrm{~Hz}$ both in the summit and in the peripheral stations.

2. Focusing on the time intervals of sustained lava fountain, the centroids obtained applying the site effect corrections are shifted towards SW (and at lower altitude in the frequency band 1-2 Hz) than those obtained without corrections. The higher $\mathrm{R}^{2}$ values and the shorter distances from NSEC at least for the band 1-2 $\mathrm{Hz}$ confirm that the site corrections improved the location results.

3. The comparison of the contour of the volcanic tremor amplitude isolines between the 1-2 $\mathrm{Hz}$ and 5-10 Hz frequency bands likely confirms that at high frequencies the seismic scattering, caused by topography and medium heterogeneity, masks eventual source directivity and makes valid the assumption of isotropic radiation [Kumagai et al., 2010; 2011]. However, we cannot exclude that the different isotropic/anisotropic features of the amplitude distribution could be due to different source geometries/orientations in the two distinct portions of plumbing system, generating low and high frequency volcanic tremor.

4. Focusing on the median values of the centroid coordinates calculated with SAF correction in the frequency band $1-2 \mathrm{~Hz}$, and in particular on the altitudes, two different periods were identified: (i) the first one (July 25 - August 20) characterized by altitudes higher than $2 \mathrm{~km}$ a.s.l., while (ii) the second one (August 20 - November 15) by lower altitudes. Such an observation, integrated with volcanological (and in particular the inter-times between fountain episodes) and geodetic data, was interpreted as resulting from gas-rich magma recharge from depth taking place during the first period.

Acknowledgements. We are indebted to the technicians of the INGV, Osservatorio Etneo for enabling the acquisition of seismic data. A.C. thanks the project ICE-VOLC (PNRA14_00011) funded by Programma Nazionale Ricerche in Antartide. SG has been supported by grants FIR 2014. We thank two anonymous reviewers for their detailed comments and fruitful suggestions.

\section{REFERENCES}

Almendros, J., B. Chouet and P. Dawson (2001). Spatial extent of a hydrothermal system at Kilauea Volcano, Hawaii, determined from array analyses of shallow long-period seismicity 1 . Method, J. Geophys. Res. 
106(B7), 13565-13580.

Alparone, S., D. Andronico, L. Lodato and T. Sgroi (2003). Relationship between tremor and volcanic activity during the Southeast Crater eruption on Mount Etna in early 2000, J. Geophys. Res., 108(B5), 22412253.

Bath, M. (1974). Spectral Analysis in Geophysics, Elsevier, Amsterdam, 563 pp.

Battaglia, J. and K. Aki (2003). Location of seismic events and eruptive fissures on the Piton de la Fournaise volcano using seismic amplitudes, J. Geophys. Res., 108(B8), doi: 10.1029/2002JB002193.

Battaglia, J., K. Aki and V. Ferrazzini (2005). Location of tremor sources and estimation of lava output using tremor source amplitude on the Piton de la Fournaise volcano: 1. Location of tremor sources, J. Geophys. Res., 147, 268-290.

Behncke, B., S. Branca, R.A. Corsaro, E. De Beni, L. Miraglia and C. Proietti (2014). The 2011-2012 summit activity of Mount Etna: Birth, growth and products of the new SE crater, J. Volcanol. Geotherm. Res.,270, 10-21.

Cannata, A., A. Catania, S. Alparone and S. Gresta (2008). Volcanic tremor at Mt. Etna: Inferences on magma dynamics during effusive and explosive activity, J. Volcanol. Geotherm. Res., 178, 19-31.

Cannata, A., G. Di Grazia, P. Montalto, F. Ferrari, G. Nunnari, D. Patanè and E. Privitera (2010). New insights into banded tremor from the 2008-2009 Mount Etna eruption, J. Geophys. Res., 115, B12318, doi:10.1029/2009JB007120.

Cannata, A., G. Di Grazia, M. Aliotta, C. Cassisi, P. Montalto and D. Patanè (2013). Monitoring seismo-volcanic and infrasonic signal at volcanoes: Mt. Etna case study, Pure Appl. Geophys., 170, 1751-1771.

Cannavò, F., A. Cannata, C. Cassisi, G. Di Grazia, P. Montalto, M. Prestifilippo, E. Privitera, M. Coltelli and S. Gambino (2017). A multivariate probabilistic graphical model for real-time volcano monitoring on Mount Etna, J. Geophys. Res., 122, doi:10.1002/2016JB013512.

Chouet, B. (1996). New methods and future trends in seismological volcano monitoring, Monitoring and Mitigation of volcano hazards, R. Scarpa and R.l. Tilling (Editors), pp. 23-97.

Chouet, B. and R. Matoza (2013). A multi-decadal view of seismic methods for detecting precursors of magma movement and eruption, J. Volcanol. Geotherm. Res., 252, 108-175.

D’Agostino, M., G. Di Grazia, F. Ferrari, H. Langer, A. Messina, D. Reitano and S. Spampinato (2013). Volcano monitoring and early warning on Mt. Etna,
Sicily based on volcanic tremor: methods and technical aspects, Complex Monitoring of Volcanic Activity ISBN: 978-1-62417-985-3 Editor: V.M. Zobin ( 2013 Nova Science Publishers, Inc., pp.53-92.

Di Grazia, G., S. Falsaperla and H. Langer (2006). Volcanic tremor location during the 2004 Mount Etna lava effusion, J. Geophys. Res., 33 L04304.

Efron, B. (1982). The Jackknife, the Bootstrap and Other Resampling Plans, Soc. for Ind. and Appl. Math., Philadelphia, Pa.

Gottschammer, E. and 1. Surono (2000). Locating tremor and shock sources recorded at Bromo volcano, J. Volcanol. Geotherm. Res., 101,199-209.

Jones, J.P., R. Carniel and S.D. Malone (2011). Decomposition, location, and persistence of seismic signals recovered from continuous tremor at Erta'Ale, Ethiopia, J. Volcanol. Geotherm. Res., doi:10.1016/j.jvolgeores.2011.07.007.

Kumagai, H., M. Nakano, M. Takuto, H. Yepes, P. Palacios, M. Ruiz, S. Arrais, M. Vaca, 1. Molina and T. Yamashima (2010). Broadband seismic monitoring of active volcanoes using deterministic and stochastic approaches, J. Geophys. Res., 115, B08303.

Kumagai, H., T. Saito, G. O’Brien and T. Yamashima (2011). Characterization of scattered seismic wavefields simulated in heterogeneous media with topography, J. Geophys. Res., 116, B03308.

Langer, H., S. Falsaperla, A. Messina, S. Spampinato and B. Behncke (2011). Detecting imminent eruptive activity at Mt Etna, Italy, in 2007-2008 through pattern classification of volcanic tremor data, J. Volcanol. Geotherm. Res., 200, 1-17.

Matsubara, W., K. Yomogida, J. Koyama, M. Kasahara, M. Ichiyanagi, H. Kawakatsu and M. Yamamoto (2004). Distribution and characteristics in waveform and spectrum of seismic events associated with the 2000 eruption of Mt. Usu, J. Volcanol. Geotherm. Res., 136, 141-158.

McNutt, S. (1987). Volcanic tremor at Pavlof volcano, Alaska, October 1973 - April 1986, Pure Appl. Geophys. 125, 6, 1051-1077.

McNutt, S. (1992). Volcanic tremor, Encyclopedia of earth system science Vol.4, pp. 417-425.

McNutt, S. (2005). Volcanic Seismology, Annu. rev. Earth Planet.Sci., 32, 461-491.

McNutt, S. and T. Nishimura (2008). Volcanic tremor during eruptions: Temporal characteristics, scaling and constraints on conduit size and processes, J. Volcanol. Geotherm. Res., 178, 10-18.

Messina, A. and H. Langer (2011). Pattern recognition of volcanic tremor data on Mt. Etna (ltaly) with KK Analysis A software program for unsupervised clas- 
sification, Computers \&t Geosciences, 37, 953-961. Metaxian, J.-P., P. Lesage and J. Dorel (1997). The permanent tremor of Masaya volcano, Nicaragua: wave field analysis and source location, J. Geophys. Res. 102, 22529-22545.

Neuberg, J. and T. Pointer (2000). Effects of volcano topography on seismic broad-band waveforms, Geophys. J. Int. 143, 239-248.

Patanè, D., G. Di Grazia, A. Cannata, P. Montalto and E. Boschi (2008). Shallow magma pathway geometry at Mt. Etna volcano, Geochem. Geophys. Geosyst., 9, Q12021, doi:10.1029/2008GC002131.

Patanè, D., A. Aiuppa, M. Aloisi, B. Behncke, A. Cannata, M. Coltelli, G. Di Grazia, S. Gambino, S. Gurrieri, M. Mattia and G. Salerno (2013). Insights into magma and fluid transfer at Mount Etna by a multiparametric approach: A model of the events leading to the 2011 eruptive cycle, J. Geophys. Res., 118, 35193539.

Privitera, E., T. Sgroi and S. Gresta (2003). Statistical analysis of intermittent volcanic tremor associated with the September 1989 summit explosive eruptions at Mount Etna, Sicily, J. Volcanol. Geotherm. Res., 120,235-247.

Spampinato, L., M. Sciotto, A. Cannata, F. Cannavo, A. La Spina, M. Palano, G. G. Salerno, E. Privitera, and T. Caltabiano (2015). Multiparametric study of the February-April 2013 paroxysmal phase of Mt. Etna New South-East crater, Geochem. Geophys. Geosyst., 16, doi:10.1002/2015GC005795.

Sparks, R.S.J., J. Biggs and J.W. Neuberg (2012). Monitoring Volcanoes, Science: vol. 335, 6074, 13101311. doi: 10.1126/science. 1219485.

Viccaro, M., 1. Garozzo, A. Cannata, G. Di Grazia and S. Gresta (2014). Gas burst vs. gas-rich magma recharge: A multidisciplinary study to reveal factors controlling triggering of the recent paroxysmal eruptions at Mt. Etna, J. Volcanol. Geotherm. Res.,278-279, 1-13.

"CORRESPONDING AUTHOR: Salvatore MOSCHELLA, Dipartimento di Scienze Biologiche, Geologiche, e Ambientali Università degli Studi di Catania, Catania, Italy email: moschellasalvo@gmail.com (ㄷ) 2018 the Istituto Nazionale di Geofisica e Vulcanologia. All rights reserved. 